\title{
Research on Behavior of Lenders and Borrowers in Online P2P Lending
}

\author{
Lulu Tan ${ }^{\mathrm{a}, *}$, Qingguo Tang ${ }^{\mathrm{b}}$ \\ School of Economics and Management, Nanjing University of Science and Technology, Nanjing \\ 210094, China; \\ a2579770265@qq.com, ${ }^{\text {a }}$ tangqguo@163.com
}

Keywords: online P2P lending, evolutionary game, behavior of borrowers and lenders.

Abstract: Online P2P lending is an emerging financial mode that combines the Internet with private lending to provide unsecured lending among individuals. Interest rates and risks determine the behavioral choices and games of lenders and borrowers in the online P2P lending. This paper proposes an evolutionary game model based on lender's investment behavior and borrower's credit choice, and uses MATLAB software to carry out numerical simulation. Then it can be found that the evolutionary behavior of online lenders and borrowers is caused by the rate of return and the cost of defaulting. Finally, it is suggest that lenders do not pursue the borrowing target with high interest rates blindly. At the same time, the P2P platform should strengthen the credit review of the borrowers and increase the borrowers' defaulting cost.

\section{Introduction}

As a new financial mode, P2P lending reduces the financing costs and removes financing thresholds, alleviates the financing dilemma of individuals and micro-enterprises. Therefore, $\mathrm{P} 2 \mathrm{P}$ lending has developed rapidly since 2013 in China. Well-known P2P lending platforms include PaiPaiDai and RenRenDai. However, Because of the lack of legal and regulatory policies, non-standardized technical operations, imperfect credit system, and asymmetric information, online P2P lending brings many issues, such as legal and regulatory risk, technological risk, management risk, and credit risk, which have affected its development. According to the data of the Online Lending House, there were hundreds of platforms running, liquidating or overdue behaviors in June 2018, many of which have many large platforms of millions of assets. The risk of online P2P lending have seriously damaged the interests of investors, hurt investors' trust and inhibited the development of the online P2P lending in China.

\section{Literature Review}

Most prior research explored the herd behavior of lenders, and more take the qualitative analysis 
and empirical research. Herzenstein and Dholakia (2011) proved that online lenders have strategic herding behavior through empirical research in [1]. Lee E and Lee B (2012) analyzed the influencing factors of lender behavior choice by establishing multiple logit market share models, which proved that the P2P lending market does have herd behavior in [2]. Lin and Luo (2013) argue that lenders prefer to bid on higher-paying loans follow their friends, but this behavior will damage their own interests. Domestic scholars try to use game theory to study the behavior of borrowers and lenders in online P2P lending in [3]. Liu (2017) proposes an evolutionary behavior forecasting model for online participants in [4]. Niu Feng and Yang Li (2016) studied the mechanism of P2P online credit risk by analyzing the behavior of both borrowers and lenders in [5]. Yang Li and Zhao Cuicui (2018) used game theory to study the mechanism of social network to alleviate credit risk in [6]. Liu Wei and Xia Liqiu (2018) studied the game behaviors based on evolutionary games in [7].

From the theory and practice perspective, we use the evolutionary game method to study the decision-making and group behavior of participants in online P2P lending. We assume that the lender has two behaviors, investing and not investing, and the borrower also has two behaviors, non-default and default, thus establishing an evolutionary model to predict their behavior and evolutionary equilibrium, then using numerical simulations to analysis the influencing factors. Finally, based on the research results, borrowers, lenders and P2P platforms are proposed some suggestions to prevent P2P lending' s risk.

\section{Hypothesis}

Smith JM and Price GR (1973) proposed evolutionary games in conjunction with biological evolution theory and game theory in [8]. They pointed out that evolutionary games study the behavior of the entire group. Participants are randomly selected from the group, and they will adjust their own strategy through the game income.

In order to analyze the behavior of online loan and establish an evolutionary game model, we have the following assumptions about the model:

(1) The game party is borrowers and lenders. There is information asymmetry in the market, borrowers have the information advantage, borrowers and lenders are all bounded rational individual, and the individual decisions are continuously adjusted;

(2) The lender has two behaviors, investing and not investing, and the borrower also has two behaviors, non-default and default;

(3) At this time, the P2P platform is a pure information intermediary platform, it only provides intermediary services, and does not participate in any activities which involving funds, nor provide guarantees, as shown below:

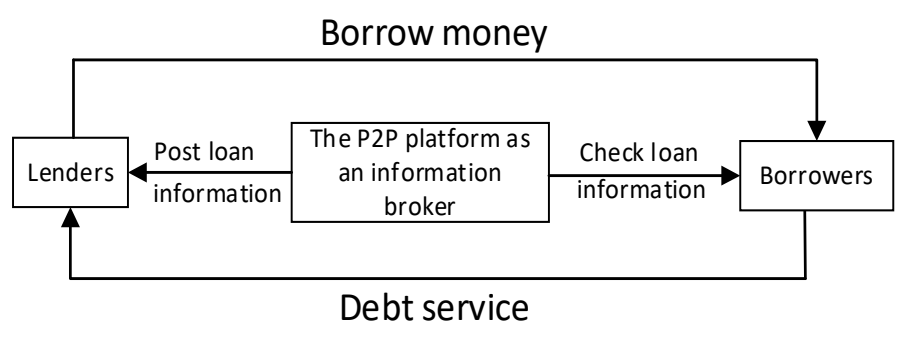

Fig. 1 P2P online lending flow chart

(4) The probability of borrower's default is X, and the probability of non-default is 1-X. At this time, the probability is not constant, but varies with time. Similarly, the probability of the lender investing is $\mathrm{Y}$, the probability of not investing is $1-\mathrm{Y}$, and the probability of investing and not investing also varies over time. 


\section{Model}

The game process is as follows: 1 . The borrower publishes the loan information; 2 . The lender screens the platform according to its own preferences, evaluates the credit of the borrower, and finally makes a decision on whether to lend money, and the decision at this time will be adjusted continuously based on the behavior of the borrower; 3. After the loan is successful, the project starts, and when the project is over, the borrower decides whether to repay the principal and interest on time. According to the assumption in 2, we can get the payment income matrix of both the borrower and the lender's game as shown in Table 1:

Table 1 Return matrix

\begin{tabular}{|c|c|c|}
\hline \multirow{2}{*}{ Lenders } & Default & Borrowers \\
\cline { 2 - 3 } & $(-\mathrm{M}, \mathrm{M} *(1-\mathrm{k})+\mathrm{R}-\mathrm{C})$ & $(\mathrm{M} \mathrm{I}, \mathrm{R}+\mathrm{Mk}-\mathrm{M} *(\mathrm{f}+\mathrm{I}))$ \\
\hline Invest & $(0,-\mathrm{C})$ & $(0,0)$ \\
\hline Do not invest &
\end{tabular}

Where the loan amount is for borrowers is $\mathrm{M}$, the expected return of lenders is $\mathrm{R}$, The loan interest rate of P2P platform is I, the closing costs when the borrower is non-default is $\mathrm{f}, \mathrm{C}$ is the disguise cost when the default borrower want to enter the market, $\mathrm{k}$ is the influence coefficient of borrowers' credit, the influence degree of the borrower repayment billed on their credit, if the breach penalty for -Mk, faithful reward for Mk.

The expected return of the borrower's choice of default:

$$
\mathrm{Ex}=\mathrm{Y} *[\mathrm{M} *(1-\mathrm{k})+\mathrm{R}]-\mathrm{C}
$$

The expected return of the borrower's choice of non-default:

$$
\mathrm{E} 1-\mathrm{X}=\mathrm{Y} *[\mathrm{R}+\mathrm{Mk}-\mathrm{M} *(\mathrm{f}+\mathrm{I})]
$$

Then the average return of the borrower:

$$
\mathrm{E} 1=\mathrm{X} * \mathrm{Ex}+(1-\mathrm{X}) * \mathrm{E} 1-\mathrm{X}=\mathrm{X} * \mathrm{Y} * \mathrm{M} *(1-2 \mathrm{k}+\mathrm{f}+\mathrm{I})-\mathrm{X} * \mathrm{C}+\mathrm{Y} *[\mathrm{k}+\mathrm{M} *(\mathrm{k}-\mathrm{f}-\mathrm{I})]
$$

The replicative dynamic equation with the proportion of $\mathrm{X}$ to choose the default strategy among the borrowers is as follows:

$$
\mathrm{F}(\mathrm{X})=\mathrm{dx} / \mathrm{dt}=\mathrm{X} *(1-\mathrm{X}) *\left[\mathrm{Y}^{*} \mathrm{M} *(1+\mathrm{f}+\mathrm{I}-2 \mathrm{k})-\mathrm{C}\right]
$$

The expected return on which the lender chooses to invest:

$$
\mathrm{EY}=-\mathrm{M}^{*} \mathrm{X}+(1-\mathrm{X}) * \mathrm{M} * \mathrm{I}
$$

The expected return on which the lender chooses not to invest:

$$
\mathrm{E} 1-\mathrm{Y}=0
$$

The average return of the lender:

$$
\mathrm{E} 2=\mathrm{Y} * \mathrm{EY}+(1-\mathrm{Y}) * \mathrm{E} 1-\mathrm{Y}=\mathrm{Y} *[-\mathrm{M} * \mathrm{X}+(1-\mathrm{X}) * \mathrm{M} * \mathrm{I}]
$$

The replicating dynamic equation of choosing the proportion of investment strategy $\mathrm{Y}$ among the lenders is as follows:

$$
\mathrm{S}(\mathrm{Y})=\mathrm{dy} / \mathrm{dt}=\mathrm{Y} *(1-\mathrm{Y}) *[\mathrm{M} * \mathrm{I}-\mathrm{X} * \mathrm{M} *(1+\mathrm{I})]
$$

In the case of incomplete information symmetry, in the P2P online lending, the borrower and the lender play games in certain rules in order to maximize their own interests. The game process in 
which the borrower chooses to default or non-default can be described by the replicating dynamic equation (4). The game process of the lender choose to invest can be described by (8).In this process the borrower and the lender adjust their strategy to a stable state. Jacobian matrix corresponding to this game is as follows:

$$
J=\left|\begin{array}{cc}
(1-2 X)[Y M(1+f+I-2 k)-C] & X(1-X) M(1+f+I-2 k) \\
-Y(1-Y) M(1+I) & (1-2 Y)[\mathrm{MI}-\mathrm{XM}(1+\mathrm{I})]
\end{array}\right|
$$

According to the determinant and trace of Jacobi matrix, five equilibrium points can be obtained $(0,0),(0,1),(1,0),(1,1),(\mathrm{E}, \mathrm{F})$. Where $\mathrm{E}=\mathrm{I} / 1+\mathrm{I}, \mathrm{F}=\mathrm{C} / \mathrm{M}(1+\mathrm{f}+\mathrm{I}-2 \mathrm{k})$.

Based on the above analysis of the evolutionary game behavior of both lenders and borrowers, we can get the evolutionary trajectory of the dynamic game behavior of both parties. As show below:

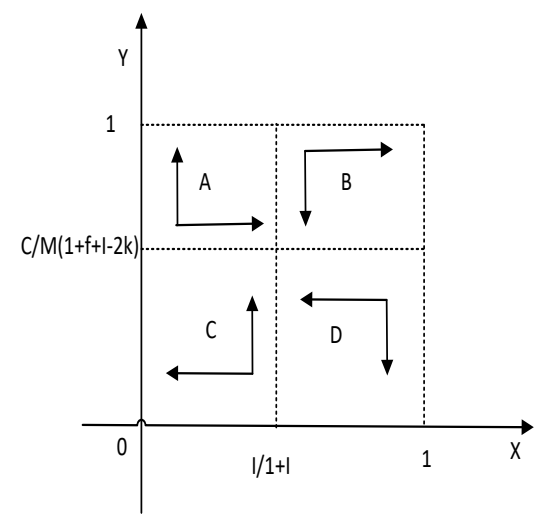

Fig. 2 Evolution of dynamic game behavior of parties

These five states are not all evolutionary stability strategies of the system. Then we need to analyze the local stability of the strategy equilibrium point. When the value of the conditional determinant is greater than zero and the trace is less than zero, it can be determined that the strategy is an evolutionary stability strategy. Therefore, the local stability of the five equilibrium points can be analyzed.

Table 2 Equilibrium point stability analysis

\begin{tabular}{|c|c|c|c|c|}
\hline Equilibrium & $(\mathrm{F} 11, \mathrm{~F} 22)$ & $\operatorname{Det}(\mathrm{J})$ & $\operatorname{Tr}(\mathrm{J})$ & Result \\
\hline$(0,0)$ & $(-,+)$ & - & $\times$ & Saddle point \\
\hline \multirow{2}{*}{$(0,1)$} & $(+,-)$ & - & $\times$ & Saddle point \\
\cline { 2 - 5 } & $(-,-)$ & + & - & Stable point \\
\hline \multirow{2}{*}{$(1,0)$} & $(-,-)$ & - & $\times$ & Saddle point \\
\hline \multirow{2}{*}{$(1,1)$} & $(+,+)$ & + & + & Unstable Point \\
\cline { 2 - 5 } & $(-,+)$ & - & $\times$ & Saddle point \\
\hline$($ E , F) & $\times$ & $\times$ & 0 & Saddle point \\
\hline
\end{tabular}

It can be seen from the above table, the game model had a stable point $(0,1)$ that is (non-default, investment). When the P2P platform gives higher packaging cost to the borrower, that is to say, the P2P platform strengthens the credit audit of the loan application, and the credit evaluation system of the platform is perfect enough to increase the cost of packaging the information of the defaulting borrower. The average profit of borrowers who chooses to default less than the borrowers who choose to non-default, so in this case the borrower chooses "non-default". At the same time, when 
most borrowers choose to repay on time, the lender will choose to invest, because the return of investment strategy is higher than that of non-investment, and "investment" is the best strategy. The borrower obeys the credit and repays money timely, the online P2P platform fund liquidity is good, also enhanced the P2P industry overall image, the investor investment information enhancement, one after another chooses the investment, at this time, online P2P lending have a healthy prosperity development.

\section{Simulation}

The game model is numerically tested to analyze the influence of P2P network loan platform on the borrower's audited intensity and the loan interest rate on the evolution result.

(1) The impact of disguise cost of borrowers on evolutionary results in P2P online lending

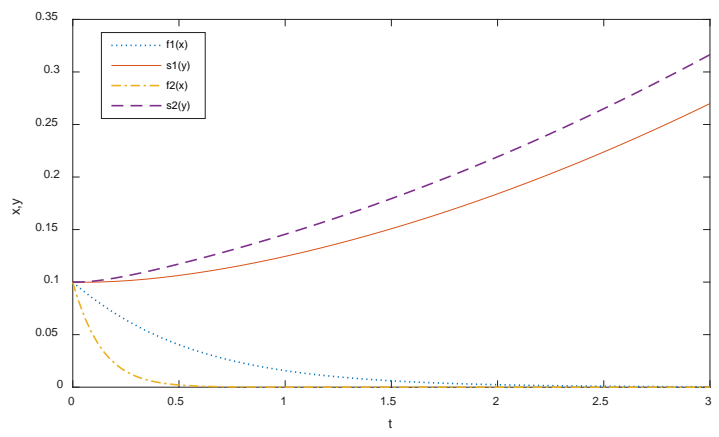

Fig. 3 The impact of disguise cost of borrowers on evolutionary results

Assume $\mathrm{M}=5, \mathrm{R}=6, \mathrm{I}=10 \%, \mathrm{f}=1 \%, \mathrm{k}=0.5$. When $\mathrm{C}=2$, to the borrower, the replicating dynamic equation of the defaulting strategy is $\mathrm{f} 1(\mathrm{x})$, to the lender, the replicating dynamic equation of the investment strategy is $\mathrm{s} 1(\mathrm{y})$. When $\mathrm{C}=8$, to the borrower, the replicating dynamic equation of the defaulting strategy is $\mathrm{f} 2(\mathrm{x})$, to the lender, the replicating dynamic equation of the investment strategy is s2(y). As we can see from the figure3, when the platform increases the disguise cost of borrowers, investors increase the possibility of investment as the disguise costs of defaulting borrowers increase, and borrowers tend to non-default with the increase of disguise costs. The whole system converges towards a good mode, and the overall risk of the system is reduced. The enhancement of the auditing of loan information accelerates the evolution of the system to a good mode (non-default, investment). Increased the borrower' $s$ tendency to non-default and the lender' $s$ tendency to investment probability. Form a great online P2P lending' s mode.

(2) The influence of lending rate on evolutionary results in P2P online lending

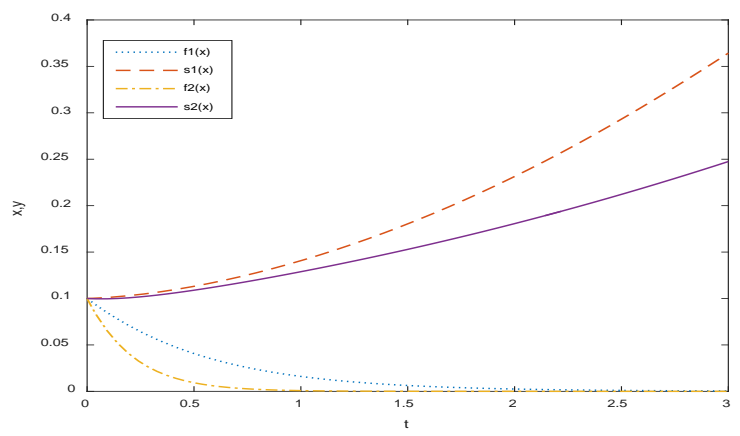

Fig. 4 The influence of lending rate on evolutionary result

Assume $M=5, R=6, f=1 \%, k=0.5$, when $I=13 \%$, to the borrower, the replicating dynamic equation 
of the defaulting strategy is $\mathrm{f1}(\mathrm{x})$, to the lender, the replicating dynamic equation of the investment strategy is $s 1(y)$. When $I=8 \%$, to the borrower, the replicating dynamic equation of the defaulting strategy is $\mathrm{f2}(\mathrm{x})$, to the lender, the replicating dynamic equation of the investment strategy is s2(y). The simulation results in figure 4 shows that as the lending rate increases, lenders tend to choose investment strategies, that is, investors tend to invest in the higher interest rate of the loan. However, as the interest rate increases, the probability of borrowers choosing default also increases with it. This is the problem of adverse selection in the loan market. Lenders tend to invest in borrowers with higher interest rates, and borrowers with higher interest rates tend to have a greater tendency to default. Non-defaulting borrowers have gradually withdrawn from the market because of their failure to borrow money, leaving borrowers with a high probability of default in the market. The phenomenon of "Bad money drives out good" has emerged in the P2P lending market, which has increased the risk of the online P2P lending market. It hinders the healthy development of online P2P lending industry.

\section{Conclusion}

Under the condition of information asymmetry and limited rationality between the two parties, this paper establishes an evolutionary game model for both borrowers and lenders under the information sharing mechanism by using evolutionary game method. Through the analysis of the replication dynamic equation and the final evolutionary equilibrium point, it is found that the greater the lending rate, the more the borrowers defaults and the more lenders tend to invest. The higher the disguise cost of borrowing for defaulting borrowers, the more the borrowers tend to repay on time. Above all, we can sum up that the sharing of credit information among lenders, and the reputation loss of borrower default, the more effective the promotion (non-default, investment) strategy becomes evolutionary stable equilibrium point, the borrower's strategy evolves to repay on time, the lender's strategy evolves to invest. Based on the above evolutionary game analysis, we proposes the following suggestions.

From the game analysis of borrowers and lenders, it is known that when other conditions remain unchanged, lenders generally prefer high-interest investment targets, and high interest rates always hide high risks. In the real online P2P lending market, investors lack understanding of information or blindly pursue high returns and easily ignore the risks. Therefore, firstly, lenders must cultivate their scientific risk-revenue awareness firmly, treat online P2P lending risks correctly, and match investment risks and returns according to their own risk tolerance organically, so as to pursue higher risks under the premise of risk controllable, they also should pursue stable lending rate rather than high lending rate; secondly, Public should strengthen risk warning education for lenders, improve

lenders' risk identification ability for problematic platforms and non-defaulting borrowers. In order to reduce the investment risk, P2P lending platforms should guide lenders to diversify investment and avoid credit risks as possible as they can. In addition, reducing the amount of a single investment and diversification can spread risk and reduce loss effectively.

\section{Acknowledgments}

The authors would like to thank the anonymous reviewers for their very valuable comments. This work was supported by the Funded Program of National Social Science Foundation of China (16BTJ019), Ministry of Education Humanities and Social Sciences Research Funding Project (14YJA910004) and Jiangsu Provincial Natural Science Foundation Funded Project (BK20151481).

\section{References}

[1] Michal Herzenstein, Utpal M. Dholakia, and Rick L. Andrews, Strategic Herding Behavior in Peer-to-Peer Loan 
Auctions, Journal of Interactive Marketing , 25 (2011) 27-36.

[2] Eunkyoung Lee, Byungtae Lee. Herding behavior in online P2P lending: An empirical investigation, Electronic Commerce Research \&Applications, 11 (2011) 495-503.

[3] Binjie Luo, Zhangxi Lin. A decision tree model for herd behavior and empirical evidence from the online P2P lending market, Inf Syst E-Bus Manage, 11(2013) 141-160.

[4] Wei Liu, and Liqiu Xia. An Evolutionary Behavior Forecasting Model for Online Lenders and Borrowers in Peer-to-Peer Lending, Journal of Operational Research, 34 (2017) 1-14.

[5] Feng Niu , Li Yang. Analysis of P2P Lending Credit Risk Generation Mechanism Based on Game Theory, Finance \& Banking, 1(2016) 1-6.

[6] Li Yang, Cuicui Zhao. Study on credit risk mitigation mechanism of P2P lending based on social network, Chinese Journal of Management Science, 1 (2018) 47-56.

[7] Wei Liu, and Liqiu Xia. Evolutionary Game Equilibrium Analysis of Participating Subject Behavior Strategies in Internet Lending Market_B_Based on the Perspective of Three-Party Game, Chinese Journal of Management Science, 5 (2018) 169-177.

[8] Smith J M, Price G R. The Logic of Animal Conflicts, Nature, 11 (246) (1973). 